\title{
A Pilot Study on Prostate Cancer Risk and Pro-Inflammatory Genotypes: Patho- physiology and Therapeutic Implications
}

\author{
C.R. Balistreri ${ }^{1}$,C. Caruso ${ }^{1}$, G. Carruba ${ }^{1,2}$, V. Miceli ${ }^{1,2}$, I. Campisi ${ }^{2}$, F. Listì ${ }^{1}$, D. Lio ${ }^{1}$, G. Colonna-Romano ${ }^{1}$, \\ and G. Candore ${ }^{1, *}$
}

${ }^{1}$ Immunosenescence Group, Department of Pathophysiology and Biomedical Methodologies, University of Palermo, Palermo, Italy and ${ }^{2}$ Experimental Oncology, Department of Oncology, ARNAS-Civico, Palermo, Italy

\begin{abstract}
Host genetic factors are crucial risk determinants for many human cancers. In this framework, an interesting model is represented by prostate cancer (PC), which is featured by a complex pathophysiology with a strong genetic component. Multiple genes seem to influence PC risk and several single nucleotide polymorphisms (SNPs) of candidate genes modifying PC susceptibility have been identified. It is noteworthy the potential association of common SNPs in pro-inflammatory genes with PC risk, since chronic inflammation is assumed to play a key role in prostate carcinogenesis. With the aim to identify candidate genes as an experimental basis to develop new strategies for both prevention and treatment of PC, we have investigated the potential role of common SNPs of a gene cluster (TLR4, TLR2, PTGS2 and 5-Lo), involved in innate and inflammatory response, in PC cases, age-matched controls and centenarians from Sicily. Six SNPs were genotyped and their association with PC risk determined. Statistical analysis evidenced a significant association of some pro-inflammatory gene SNPs with an increased risk of PC. Furthermore, significant differences were observed comparing the three groups in the combined presence of a "high responder" pro-inflammatory profile. Overall, the present results suggest the likely association of these SNPs and PC risk, clearly motivating the need of larger studies to confirm the role of these genes in PC development and/or progression.
\end{abstract}

Keywords: Prostate cancer (PC), inflammation, genetics, TLR4, TLR2, PTGS2, 5-LO, SNP.

\section{INTRODUCTION}

Host genetic factors may play a critical role in the pathophysiology of many human cancers [1]. An interesting model is prostate cancer (PC), which represents the second principal cause of cancer-related deaths in Western males. It is likely that prostate cancers can take decades to progress to a clinically manifest disease, making their diagnosis and treatment difficult [2,3]. Over the last two decades, serum prostate-specific antigen (PSA) has been considered a valuable tool for PC surveillance. However, the age-adjusted mortality rates of $\mathrm{PC}$ have remained fairly constant. At the present, there is an overall consensus to consider PSA a nonspecific marker to diagnose PC. Increased serum levels of PSA have frequently been observed in several other disease states of the prostate gland than cancer [4-6]. On the other hand, different biomarkers of various stages of PC development have recently been identified as promising tools for PC diagnosis [5,7,8].

Currently, the evidence for a strong genetic background in PC development is compelling. Several case-control studies, twin studies, and segregation analyses have consistently found genetic susceptibility to PC and its clinical outcome [6,9-11]. Several candidate genes of PC risk have been identified and their interaction, either additively or epistatically, has been hypothesized. Furthermore, common single nucleotide polymorphisms (SNPs) of a series of low penetrance alleles, referred to as "genetic modifier alleles", are likely to play an important role in PC susceptibility. The list of these variants is long and the major pathways under examination include those involved in androgen action, DNA repair, carcinogen metabolism and inflammation [6]. There is also a general consensus that specific combinations of these variants, in the appropriate environmental settings, have the potential to profoundly affect the risk of PC development.

In the present study, we have assessed the potential role of some common SNPs of the Toll-Like Receptor (TLR)-4,-2, cyclo-

*Address correspondence to this author at the Department of Pathophysiology and Biomedical Methodologies, University of Palermo, Corso Tukory, 211, 90134, Palermo, Italy; Tel: +39 0916555931;

Fax: +39 0916555933; E-mail: gcandore@unipa.it; crbalistreri@unipa.it
oxygenase-(COX)-2 (described as PTGS2), and 5-lipoxygenase (5Lo) genes, all encoding molecules involved in innate immunity and inflammatory response, in PC development. Genetic variants of these genes, mostly SNPs, determine pro-inflammatory genotypes known to modulate and increase risk of chronic inflammatory states and tissue damage and to create a tissue milieu favoring carcinogenesis, there by promoting development and progression of PC. In this study, we have compared selected SNPs in PC patients, in healthy controls, and in a second control group of centenarians, "exceptional individuals", who have been able to escape major common age-related diseases, including cancer [12-14]. The results of this study could help understand the pathophysiology of PC, further clarifying the association between the genetics of inflammation and PC susceptibility. In addition, they could allow the definition of a PC high risk profile, eventually leading to both early recognition of individuals at risk of disease and identification of potential molecular targets for prevention and/or treatment.

\section{SUBJECTS AND METHODS}

\section{Patients and Controls}

The study included 50 Sicilian patients with PC at the time of their admission to the Department of Oncology of Palermo ARNAS-Civico Hospital (age range 60-80 years). Controls were 125 age-matched male Sicilians in good health according to their clinical history and blood tests (complete blood cell count, erythrocyte sedimentation rate, glucose, urea nitrogen, creatinine, electrolytes, $\mathrm{C}$ reactive protein, liver function tests, iron, proteins). A second control group consisted of 55 male centenarians (>99 years), whose age was confirmed from records at the city hall and/or church registries. No cancer or other age-related diseases were clinically detectable in the centenarians, although some had reduced auditory and visual acuity. Because immigration and intermarriage have historically been rare in the last hundred years, the ethnicity of all participants was established by all four grandparents having been born in Sicily. The study received approval from local ethic committees and all participants gave their informed consent. 


\section{Genotyping}

The study material consisted of DNA samples. The DNA samples of cancer cases were obtained by prostate tissue placed into a suitable volume of RNA-later (RNA Stabilization Reagent, Applied Biosystems, California, U.S.A.), used to purify genomic DNA and total RNA simultaneously from each single biological sample with All-Prep DNA/RNA Mini Kit (Qiagen, Dusseldorf, Germany). Tumor samples were genotyped for SNPs of the genes selected in this study. In particular, six SNPs, located in the promoter and coding regions of TLR-4,-2, PTGS2, 5-Lo genes, were analysed (Table 1).

Table 1. Genes (Accession Number), SNPs (Accession Number), and Substitutions Investigated in the Study

\begin{tabular}{|c|c|}
\hline Genes & SNPs \\
\hline \hline TLR4 (NM-138554.1) & $\begin{array}{c}\text { +896A/G (Asp299Gly; rs4986790) } \\
+1196 \mathrm{C} / \mathrm{T} \text { (Thr399Ile; rs4986791) }\end{array}$ \\
\hline TLR2 (NM 003264) & $\begin{array}{c}+2408 \mathrm{G} / \mathrm{A} \text { (Arg753Gln; rs5743708) } \\
+2029 \mathrm{C} / \mathrm{T} \text { (Arg677Trp; no rs available } \\
\text { designation) }\end{array}$ \\
\hline $\begin{array}{c}\text { PTGS2 (NM-000963) } \\
\text { (Cox-2 gene) }\end{array}$ & $\begin{array}{c}-765 \mathrm{G} / \mathrm{C} \text { (rs20417) } \\
\text { 5-Lo (NM000698) }\end{array}$ \\
\hline
\end{tabular}

The DNA samples of the two control groups had been previously extracted from blood samples and genotyped for the six SNPs. The procedure for detecting the $+896 \mathrm{~A} / \mathrm{G}$ and $+1196 \mathrm{C} / \mathrm{T}$ TLR4 and +2408 G/A and +2029C/T TLR2 SNPs (Table 1) was based on Restriction Fragment Length Polymorphism-PCR (RFLPPCR), restriction cleavage with Nco I, Hinf I, Mwo I and Mps I respectively (New England Biolabs, USA), and separation of DNA fragments by electrophoresis, as previously described $[15,16]$. The genotyping of -765G/C PTGS2 SNP was performed using RFLPPCR and with Aci I (New England Biolabs, USA) restriction enzyme, as previously reported [17]. An allele refractory mutation system (ARMS)-PCR was utilised to determine the -1708 G/A 5-Lo SNP, as previously described [17].

\section{Statistics}

Allelic and genotypic frequencies were evaluated by gene count. The data were tested for the goodness of fit between the observed and expected genotype frequencies according to HardyWeinberg equilibrium, by $\chi^{2}$ test. Significant differences in frequencies among the three groups were calculated by $\chi^{2}$ (by $3 \times 3$, $3 \times 2$ and $2 \times 2$ tables, where appropriate). Furthermore, Odds Ratios (OR) with 95\% Confidence Intervals (CI) and their significance were calculated.

\section{RESULTS}

Tables $\mathbf{2}$ and $\mathbf{3}$ show the genotype distributions, allele frequencies and the OR $(95 \% \mathrm{CI})$ values of the TLR4 and TLR2 gene SNPs analysed in this study. Both the genotypes and the alleles of +896A/G TLR4 SNP were significantly differently distributed among the three groups $(\mathrm{p}=0.006$ and $\mathrm{p}=0.001$, respectively; Tables $\mathbf{2}$ and $\mathbf{3}$ ).

In particular, a significant difference was observed comparing the genotype distributions and allele frequencies of this SNP in patients and centenarians $(\mathrm{p}=0.002$ and $\mathrm{p}=0.0008$, respectively; $\mathrm{OR}=16.8$ (2.1-129.6; $\mathrm{p}=0.0008)$ (Tables $\mathbf{2}$ and 3). No significant differences were instead detected in the genotype distributions and allele frequencies of this SNP between patients and age-matched controls (Tables $\mathbf{2}$ and $\mathbf{3}$ ). In contrast, no significant differences were detected in the genotype distributions and allele frequencies of +1196C/T TLR4 SNP (Tables 2 and 3).

Analyzing the data of $+2408 \mathrm{G} / \mathrm{A}$ TLR2 SNP among the three cohorts, a significantly different distribution was revealed of both the genotypes and the alleles $(p=0.0007$ and $p=0.0003$, respectively) (Tables $\mathbf{2}$ and 3). In particular, a significant difference was obtained comparing patients and centenarians $(\mathrm{p}=0.004$ and $\mathrm{p}=0.002$ respectively; $\mathrm{OR}=8.3(1.8-37.2) \mathrm{p}=0.0027)$, while no significant differences were detected between patients and agematched controls (Tables 2 and 3). We did not observe any significant difference for both genotype distributions and allele frequencies of the +2029 C/T TLR2 SNP (Tables 2 and $\mathbf{3}$ ).

Tables 4 and 5 illustrate the genotype distributions, allele frequencies and the OR $(95 \% \mathrm{CI})$ values of $-765 \mathrm{G} / \mathrm{C}$ PTGS2 and 1708G/A 5-Lo SNPs in three groups enrolled in the study. Both the genotypes and the alleles of -765G/C PTGS2 SNP were differently distributed among the three groups $(p=0.01$ and $p=0.05$, respectively) (Tables $\mathbf{4}$ and 5). In particular, comparing the genotype distributions and the allele frequencies of this SNP of patients and centenarians, we observed a significant difference $(\mathrm{p}=0.03$ and $\mathrm{p}=$ 0.01, respectively; OR=2.1 (1.1-3.9 p=0.01) (Tables 4 and 5). In contrast, no significant differences were detected in the genotype distributions and allele frequencies of this SNP between patients and age-matched controls (Tables 4 and 5). Concerning the 1708G/A5-Lo SNP, both the genotypes and the alleles were differently distributed among the three groups $(\mathrm{p}=0.0004$ and $\mathrm{p}=0.0007$, respectively) (see Tables 4 and 5). In particular, there was a significant difference in the genotype distributions and the allele frequencies of this SNP between patients and centenarians $(\mathrm{p}=0.008$ and respectively $\mathrm{p}=0.0005 ; \mathrm{OR}=5.17(2-13.3 ; \mathrm{p}=0.0005)$ and between patients and controls $(\mathrm{p}=0.003$ and $\mathrm{p}=0.005$ respectively; 2.4(1.3-4.5; $\mathrm{p}=0.005$ ) (Tables 4 and 5).

In summary, these pro-inflammatory alleles were overrepresented in patients compared to healthy men and underrepresented in centenarians compared to younger healthy controls.

To identify a pro-inflammatory genetic risk profile, we evaluated the frequency of " $+896 \mathrm{~A}+\mathrm{TLR} 4 /+2408 \mathrm{G}+\mathrm{TLR} 2 /+$ 2029C+TLR2/-765G+PTGS2/-1708A+5-Lo“ high pro-inflammatory" genotype among the three cohorts. By comparing it with frequency of all other combinations, we observed that this "high responder" genotype was differently distributed among the three groups $(\mathrm{p}=0.002)$, in particular between PC patients and centenarians (36\% vs. $11 \%, \mathrm{p}=0.002 ; \mathrm{OR}=4.59(1.6-12.8), \mathrm{p}=0.004)$ (see Table 6).

\section{DISCUSSION}

$\mathrm{PC}$ is the most common non-skin malignant cancer in Western male populations. Its incidence increases rapidly in men over 50 years of age [2]. The development of PC is based on the interaction between genetic factors and the host exposure to environmental factors, such as infectious agents, dietary carcinogens and hormonal imbalances [6,18-22]. In this complex situation, chronic inflammation seems to play a key role. The chronically altered prostatic milieu is characterized by the activation of signaling pathways that represent a possible link between inflammation and carcinogenesis. Many of these factors play a dual role in the process, promoting neoplastic progression but also facilitating cancer prevention $[6,18$ 21].

To date, there are no adequate biomarkers to guide PC prognosis and treatment [3-5]. Several studies have focused on detecting candidate genes, in particular genes involved in DNA repair, carcinogen metabolism and inflammation [6], which are associated with genetic susceptibility to PC and the clinical outcome of this disease $[10,11]$. Genetic variants of these genes, 
Table 2. Genotype Distributions of +896 A/G (Asp299Gly) and $+1196 C / T$ (Thr399Ile) Polymorphisms of TLR4 Gene, and of +2029C/T (Arg677Trp) and +2408 G/A (Arg753Gln) Polymorphisms of TLR2 Gene in 50 PC Patients, 125 Age-Matched Controls and 55 Centenarians from Sicily

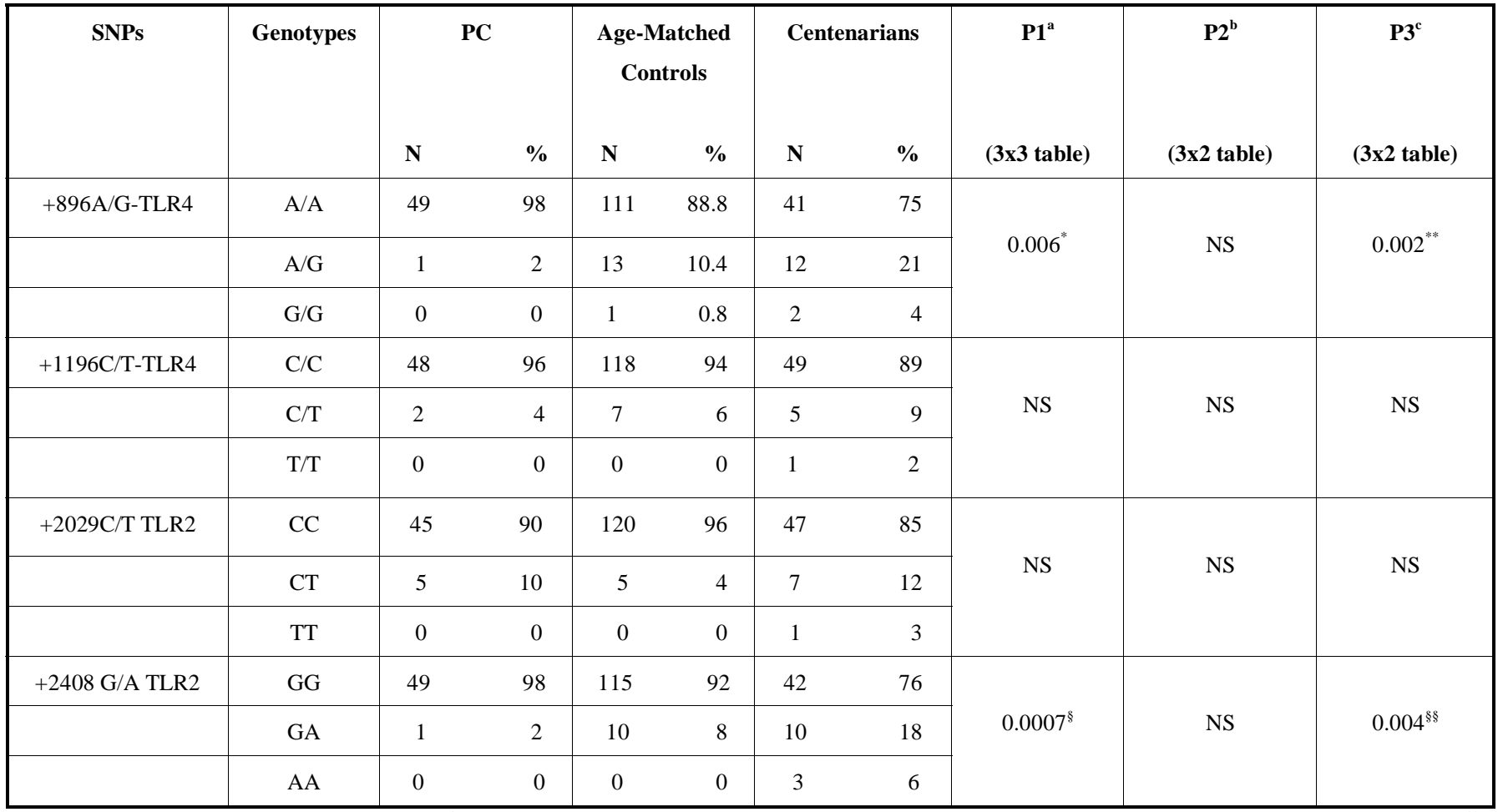

All genotypes were in Hardy-Weinberg equilibrium. "Significant differences by $\chi 2$ test in genotype distribution of +896 A/G TLR4 SNP among the three groups were found. ${ }^{* * *} \mathrm{~A}$ significant $\mathrm{p}$ value was also observed between patients and centenarians, analyzing by $\chi 2$ test the genotype distribution of this SNP. ${ }^{\S}$ The genotype distributions of $+2408 \mathrm{G} / \mathrm{A}$ TLR 2 SNP were significantly distributed among three groups, and ${ }^{\S}$ between patients and centenarians.

$\mathrm{P}^{\mathrm{a}}=$ significance values calculated by $\chi 2$ test, analyzing the data of these SNPs among the three groups

$\mathrm{P} 2^{\mathrm{b}}=$ significance values calculated by $\chi^{2}$ test, analyzing the data of these SNPs between patients and age-matched controls

$\mathrm{P}^{\mathrm{c}}=$ significance values calculated by $\chi^{2}$ test, analyzing the data of these SNPs between patients and centenarians

Table 3. Allele Frequencies of $+896 \mathrm{~A} / \mathrm{G}$ (Asp299Gly) and $+\mathbf{1 1 9 6 C} / \mathrm{T}$ (Thr399Ile) Polymorphisms of TLR4 Gene, and of $+2029 \mathrm{C} / \mathrm{T}$ (Arg677Trp) and +2408 G/A (Arg753GIn) Polymorphisms of TLR2 Gene in 50 PC Patients, 125 Age-Matched Controls and 55 Centenarians from Sicily. (2x2 Comparisons Between the Different Groups with Odd Ratio (OR) and 95\% Confidence Interval)

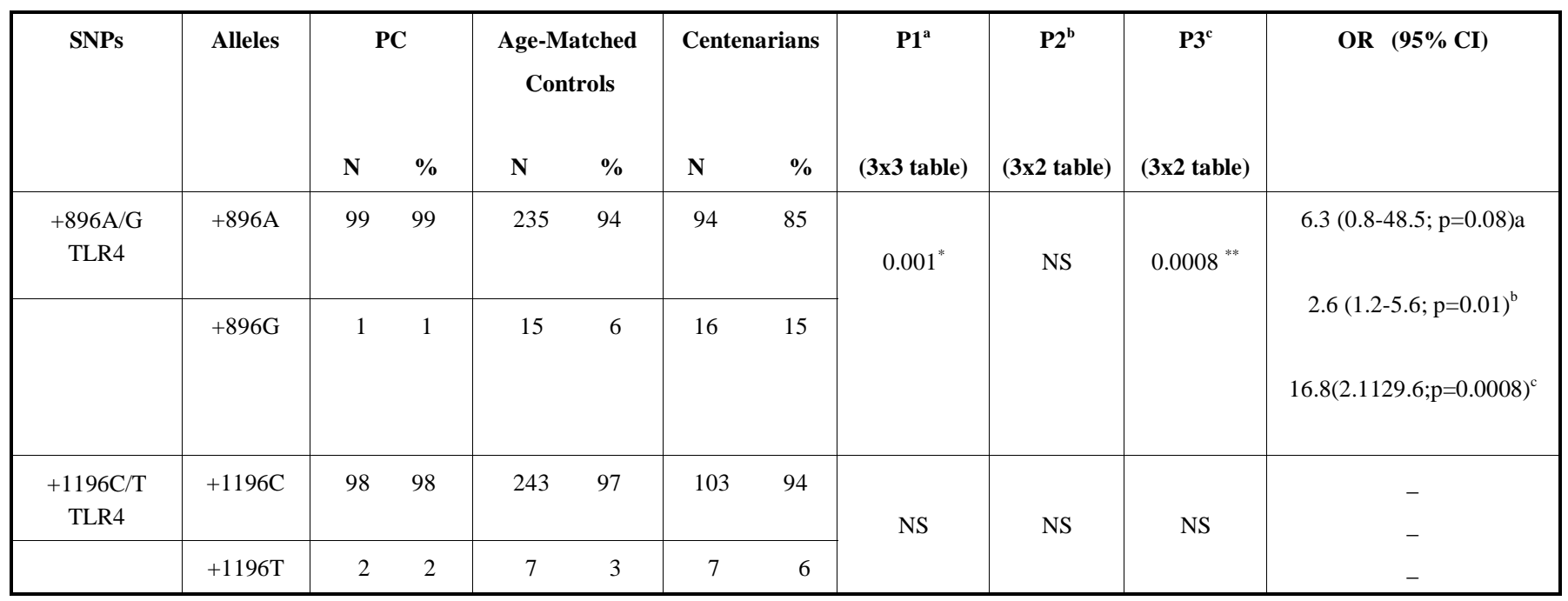


(Table 3) Contd....

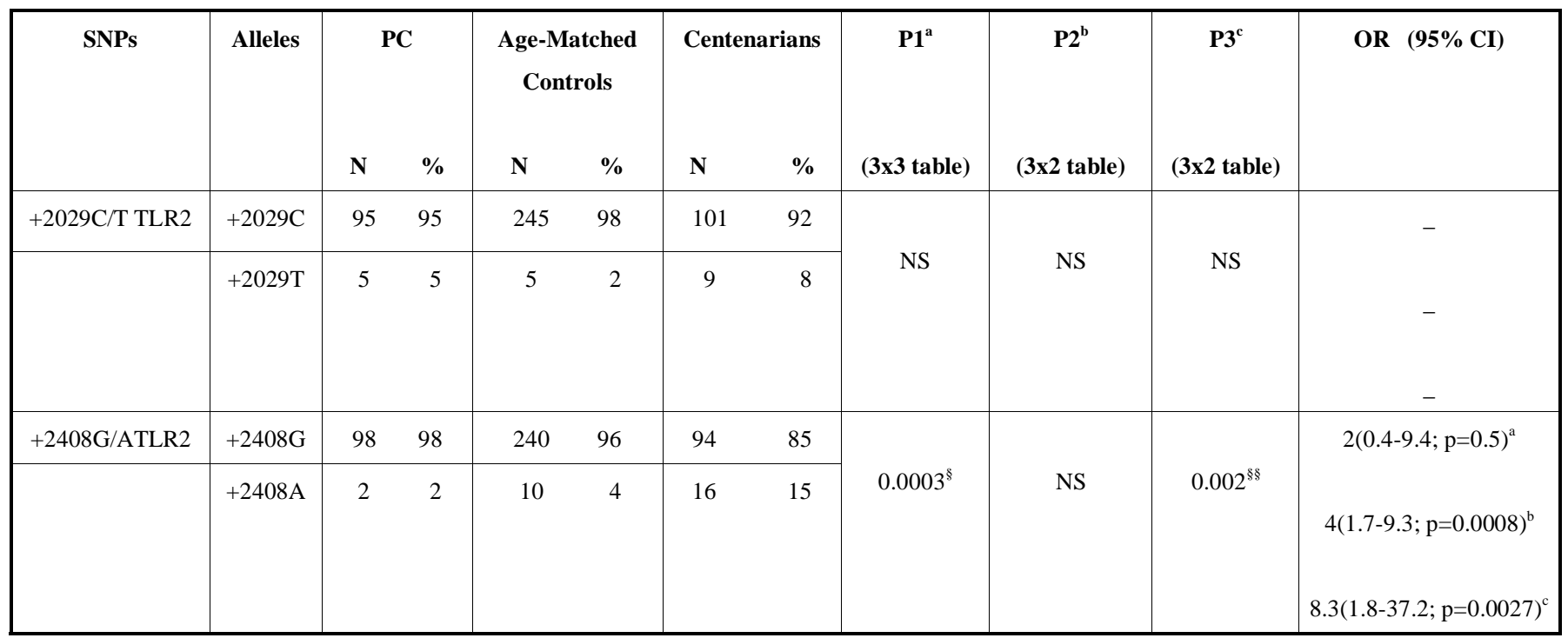

"A significant different frequency of this SNP among three groups and ${ }^{* *}$ in PC patients respect to centenarians was observed. ${ }^{\S}$ Besides, the allele frequencies of $+2408 \mathrm{G} / \mathrm{A}$ TLR2 SNP were found significantly distributed among three cohorts and ${ }^{\$ \S}$ between patients and centenarians.

$\mathrm{P} 1{ }^{\mathrm{a}}=$ significance values calculated by $\chi 2$ test, analyzing the data of these SNPs among the three groups

$\mathrm{P} 2^{\mathrm{b}}=$ significance values calculated by $\chi^{2}$ test, analyzing the data of these SNPs between patients and age-matched controls

$\mathrm{P}^{\mathrm{c}}=$ significance values calculated by $\chi 2$ test ( $3 \times 2$ table), analyzing the data of these SNPs between patients and centenarians.

In the last column we reported the OR values calculated for higher frequent alleles in PC patients vs. age-matched controls ${ }^{\mathrm{a}}$, age-matched controls vs. centenarians ${ }^{\mathrm{b}}$; PC patients vs. centenarians $^{c}$

Table 4. Genotype Distributions of -765 G/C Polymorphism of PTGS2 Gene and of -1708 G/A Polymorphism of 5-LO Gene in 50 PC Patients, 125 Age-Matched Controls and 55 Centenarians from Sicily

\begin{tabular}{|c|c|c|c|c|c|c|c|c|c|c|}
\hline SNPs & Genotypes & \multicolumn{2}{|c|}{ PC } & \multicolumn{2}{|c|}{$\begin{array}{l}\text { Age-Matched } \\
\text { Controls }\end{array}$} & \multicolumn{2}{|c|}{ Centenarians } & $\begin{array}{c}\text { P1 }^{\mathrm{a}} \\
(3 \times 3 \text { table })\end{array}$ & $\begin{array}{c}\mathbf{P 2}^{\mathbf{b}} \\
(3 \times 2 \text { table })\end{array}$ & $\begin{array}{c}\mathbf{P 3}^{\mathbf{c}} \\
(3 \times 2 \text { table })\end{array}$ \\
\hline \multirow[t]{2}{*}{-765G/C PTGS2 } & GG & 31 & 62 & 65 & 52 & 27 & 49 & \multirow{2}{*}{$0.01^{*}$} & \multirow{2}{*}{ NS } & \multirow{2}{*}{$0.03^{* *}$} \\
\hline & $\mathrm{CC}$ & 4 & 8 & 14 & 11 & 15 & 27 & & & \\
\hline -1708G/A5-Lo & GG & 30 & 60 & 98 & 78 & 49 & 89 & $0.0004^{\S}$ & $0.003^{\S \S}$ & $0.008^{\S \S \S}$ \\
\hline
\end{tabular}

All genotypes were in Hardy-Weinberg equilibrium. "Significant differences by $\chi 2$ test in genotype distribution of $-765 \mathrm{G} / \mathrm{C}$ PTGS2 SNP among the three groups were found. ${ }^{* *}$ A significant $\mathrm{p}$ value was also observed between patients and centenarians, analyzing by $\chi 2$ test the genotype distribution of this SNP. ${ }^{\S}$ The genotype distributions of -1708G/A5-Lo SNP were significantly distributed among three groups, and ${ }^{\$ \S}$ between patients and centenarians and ${ }^{\S \S}$ between patients and age-matched controls.

$\mathrm{P} 1^{\mathrm{a}}=$ significance values calculated by $\chi 2$ test, analyzing the data of these SNPs among the three groups

$\mathrm{P} 2^{\mathrm{b}}=$ significance values calculated by $\chi 2$ test, analyzing the data of these SNPs between patients and age-matched controls

$\mathrm{P}^{\mathrm{c}}=$ significance values calculated by $\chi 2$ test, analyzing the data of these SNPs between patients and centenarians 
Table 5. Allele Frequencies of -765 G/C Polymorphism of PTGS2 Gene and of -1708 G/A Polymorphism of 5-LO Gene in 50 PC Patients, 125 Age-Matched Controls and 55 Centenarians from Sicily. $2 x 2$ Comparisons Between the Different Groups with Odd Ratio (OR) and $95 \%$ Confidence Interval

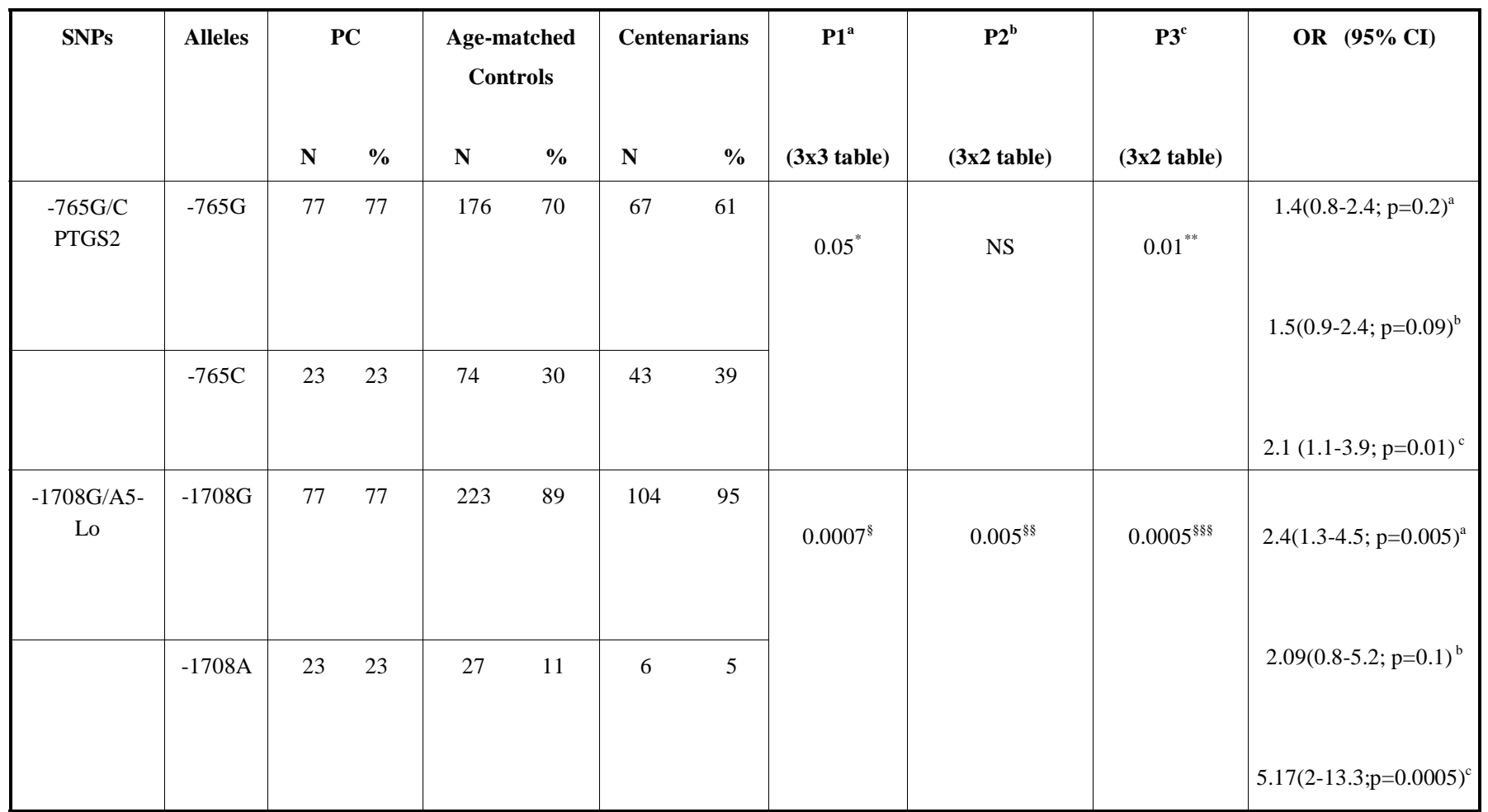

${ }^{*}$ An over-expression of $-765 \mathrm{G}$ pro-inflammatory allele among the three groups and ${ }^{* *}$ in $\mathrm{PC}$ patients respect to centenarians was observed. ${ }^{\S} \mathrm{Besides,}$ the allele frequencies of 1708G/A5-Lo SNP were found significantly differently distributed among three cohorts, and ${ }^{\S \S}$ between patients and age-matched controls and ${ }^{\$ \S}$ between patients and centenarians. $\mathrm{P}^{\mathrm{a}}=$ significance values calculated by $\chi^{2}$ test, analyzing the data of these SNPs among the three groups

$\mathrm{P} 2^{\mathrm{b}}=$ significance values calculated by $\chi 2$ test, analyzing the data of these SNPs between patients and age-matched controls

$\mathrm{P}^{\mathrm{c}}=$ significance values calculated by $\chi 2$ test, analyzing the data of these SNPs between patients and centenarians

In the last column we reported the OR values calculated for higher frequent alleles in PC patients vs. age-matched controls ${ }^{\mathrm{a}}$, age-matched controls vs. centenarians ${ }^{\mathrm{b}}$; PC patients vs. centenarians $^{\mathrm{c}}$

Table 6. The Frequency of +896A+TLR4/+2408G+TLR2/+2029C+TLR2/-765G+PTGS2/-1708A+5-Lo"High Responder"(ProInflammatory) Genotype Among the Three Cohorts

\begin{tabular}{|c|c|c|}
\hline & $\begin{array}{c}+896 \mathrm{~A}+\mathrm{TLR} 4 /+1196 \mathrm{C}+\mathrm{TLR} 4 /+2408 \mathrm{~T}+\mathrm{TLR} 2 /+2029 \mathrm{C}+\mathrm{TLR} 2 /-765 \mathrm{G}+\mathrm{PTGS2} / 1708 \mathrm{~A}+5 \mathrm{Lo} \\
\text { "high-responder"“ (pro-inflammatory) Genotype }\end{array}$ & Other Genotypes \\
\hline $\begin{array}{l}\text { Patients } \\
(\mathrm{N}=50)\end{array}$ & 18 & 32 \\
\hline $\begin{array}{l}\text { Age-matched Controls } \\
\qquad(\mathrm{N}=125)\end{array}$ & 44 & 81 \\
\hline
\end{tabular}

* Significant differences by $\chi 2$ test $(3 \times 3$ table $)$ in this genotype frequency among the three groups and between patients and centenarians $(\mathrm{p}=0.002)$ were observed.

primarily SNPs, may modulate and be associated with increased chronic inflammation and carcinogenesis of the prostate gland. In addition, they may operate in combination to create a "risk profile" [6]. It is also generally believed that such SNPs can modify the effectiveness of therapies of various age-related diseases, including PC. Accordingly, SNPs associated with polygenic traits represent a major goal of many pharmaceutical companies to discover novel therapeutic molecular targets $[23,24]$.
Based on the above considerations, we have analyzed the role in PC of six SNPs of the TLR4, TLR2, PTGS2 and 5-Lo genes, encoding molecules primarily implicated in innate immunity and inflammatory response. Our results indicate that pro-inflammatory SNPs of some of these genes are significantly associated with PC. Furthermore, we identified a risk profile in PC patients compared to centenarians, used in our study as an additional control group of "exceptional individuals" able to avoid major common age-related diseases, including cancer [12-14]. As we have previously demonstrated that alleles associated with age-related diseases are not 
included in the genetic profile favoring longevity [25,26], a genetic background promoting pro-inflammatory responses may play opposite roles in age-related diseases, including $\mathrm{PC}$, and in longevity.

On the basis of data reported herein, some inference on their translational impact can be drawn. The presence of "high-risk" alleles of the PTGS2 and the 5-LO genes may suggest the possibility of developing preventive measures using specific inhibitors of eicosanoids and/or their enzymes. For people who do not respond to (or comply with) NSAID therapy, other more sophisticated preventive approaches may be possible [6], including the use of agonists of TLR receptors in subjects who are carriers of $+896 \mathrm{~A} / \mathrm{G}$ TLR4 and +2408 G/A TLR2 SNPs. The aim of such an approach would be to block the TLR-NF- $\mathrm{KB}$ signaling pathway required for induction of inflammatory responses and the release of proinflammatory mediators. This approach might reduce the risk of PC development [6,27]. Another possible therapeutic intervention in subjects with pro-inflammatory alleles of TLR4 and TLR2 genes might be antibody-mediated stimulation of TAM receptors involved in the inhibition of the inflammatory response. The sequential induction of this pathway, and its integration with upstream TLR and cytokine signaling networks, may limit the inflammatory response and maintain innate immune system homeostasis. A better understanding of the regulatory mechanisms of this cascade may have important implications for therapeutic intervention in human immune disorders [28,29].

Although our study presents some limitations primarily related to the relatively small number of patients and controls, it compares subjects belonging to a very homogeneous population from Sicily. Thus, our data are likely to be at least as reliable as those from studies performed on larger cohorts of patients from Northern Europe or the United States, which are ethnically matched to Caucasians in general. Conversely, as discussed by Caruso et al. [6], the use of centenarians as "super-controls" might enhance the possibility of identifying the genetic profile characterizing susceptibility and/or resistance to PC. It may be argued that a Bonferroni-type adjustment should be performed to correct for testing multiple polymorphisms. However, we feel that this correction is too stringent and has the potential to ignore important observations [30]. In any case, further investigations on larger homogenous populations are needed to corroborate the present evidence.

\section{ACKNOWLEDGMENTS}

This work was supported by the Italian Ministry of Health grant (Molecular mechanisms controlling cancer stem cells survival, RFSIC-2006-335442) to G. Carruba and C. Caruso and by Ministry of Education, University and Research (formerly 60\%) grant to G. Candore and C. Caruso. The "Immunosenesence Research Group", coordinated by Prof. C. Caruso in association with the Experimental Oncology of ARNAS-Civico, was enlarged thanks to a joint contract. VM is a PhD student of Pathobiology $\mathrm{PhD}$ course (directed by C.C.) at Palermo University and this work is submitted in partial fulfillment of the requirement for the $\mathrm{PhD}$ degree.

\begin{tabular}{|c|c|c|}
\hline \multicolumn{3}{|c|}{ ABBREVIATIONS } \\
\hline ARMS-PCR & $=$ & Allele Refractory Mutation System-PCR \\
\hline $\mathrm{CI}$ & $=$ & Confidence Interval \\
\hline $\mathrm{COX}-2$ & $=$ & Cyclo-Oxygenase- 2 \\
\hline OR & $=$ & ODD Ratio \\
\hline 5-Lo & $=$ & 5-Lypoxygenase \\
\hline $\mathrm{PC}$ & $=$ & Prostate Cancer \\
\hline PSA & $=$ & Serum Prostate-specific Antigen \\
\hline PTGS2 & $=$ & $\begin{array}{l}\text { Prostaglandin E Synthase } 2 \text { gene of } \\
\text { cyclooxygenase- } 2\end{array}$ \\
\hline
\end{tabular}

RFLP-PCR = Restriction Fragment Length PolymorphismPCR

SNP $\quad=$ Single Nucleotide Polymorphism

TAM $=$ TAM receptor

TLR4 = Toll-Like Receptor-4

TLR2 = Toll-Like Receptor-2

\section{REFERENCES}

[1] Lin BK, Clyne M, Walsh M, Gomez O, Yu W, Gwinn M, et al. Tracking the epidemiology of human genes in the literature: the HuGE Published Literature database. Am J Epidemiol 2006; 164: 14.

[2] Jemal A, Siegel R, Ward E, Hao Y, Xu J, Murray T, et al. Cancer statistics, 2008. CA Cancer J Clin 2008; 58: 71-96.

[3] Maroni PD, Crawford ED. Screening for prostate cancer in 2006: PSA in the 21st century. N C Med J 2006; 67: 136-9.

[4] Barry MJ. Screening for prostate cancer--the controversy that refuses to die. N Engl J Med 2009; 360: 1351-4.

[5] Sardana G, Dowell B, Diamandis EP. Emerging biomarkers for the diagnosis and prognosis of prostate cancer. Clin Chem 2008; 54: 1951-60.

[6] Caruso C, Balistreri CR, Candore G, Carruba G, Colonna-Romano G, Di BonA D, et al. Polymorphisms of pro-inflammatory genes and Prostate Cancer risk: a pharmacogenomic approach, Cancer Immunol Immunother 2009; 58(12): 1919-33.

[7] Bensalah K, Lotan Y, Karam JA, Shariat SF. New circulating biomarkers for prostate cancer. Prostate Cancer Prostatic Dis 2008; 11: 112-20.

[8] Shariat SF, Karam JA, Margulis V, Karakiewicz PI. New bloodbased biomarkers for the diagnosis, staging and prognosis of prostate cancer. BJU Int 2008; 101: 675-83.

[9] Schaid DJ. The complex genetic epidemiology of prostate cancer. Hum Mol Genet 2004; 13: R103-21.

[10] Dong LM, Potter JD, White E, Ulrich CM, Cardon LR, Peters U. Genetic susceptibility to cancer: the role of polymorphisms in candidate genes. JAMA 2008; 299: 2423-36.

[11] Foulkes WD. Inherited susceptibility to common cancers. N Engl J Med 2008; 359: 2143-53.

[12] Cevenini E, Invidia L, Lescai F, Salvioli S, Tieri P, Castellani G, et al. Human models of aging and longevity. Expert Opin Biol Ther 2008; 8: 1393-405

[13] Vasto S, Carruba G, Lio D, Colonna-Romano G, Di Bona D, Candore $\mathrm{G}$, et al. Inflammation, ageing and cancer. Mech Ageing Dev 2009; 130: 40-5.

[14] Imyanitov EN. Use of elderly tumor-free subjects as a "supercontrol" for cancer epidemiological studies: pros and cons. Mech Ageing Dev 2009; 130: 122-7.

[15] Balistreri CR, Candore G, Lio D, Colonna-Romano G, Di Lorenzo $\mathrm{G}$, Mansueto $\mathrm{P}$, et al. Role of TLR4 receptor polymorphisms in Boutonneuse fever. Int J Immunopathol Pharmacol 2005; 18: 65560 .

[16] Balistreri CR, Candore G, Mirabile M, Lio D, Caimi G, Incalcaterra E, et al. TLR2 and age-related diseases: potential effects of Arg753Gln and Arg677Trp polymorphisms in acute myocardial infarction. Rejuvenation Res 2008; 11: 293-6.

[17] Listì F, Caruso M, Incalcaterra E, Hoffmann E, Caimi G, Balistreri $\mathrm{CR}$, et al. Pro-inflammatory gene variants in myocardial infarction and longevity: implications for pharmacogenomics. Curr Pharm Des 2008; 14: 2678-85.

[18] De Marzo AM, Platz EA, Sutcliffe S, Xu J, Grönberg H, Drake CG, et al. Inflammation in prostate carcinogenesis. Nat Rev Cancer 2007; 7: 256-69.

[19] Hold GL, El-Omar ME. Genetic aspects of inflammation and cancer. Biochem J 2008; 410: 225-35.

[20] Sutcliffe S, Platz EA. Inflammation and prostate cancer: a focus on infections. Curr Urol Rep 2008; 9: 243-9.

[21] Nelson WG, DeWeese TL, De Marzo AM. The diet, prostate inflammation, and the development of prostate cancer. Cancer Metastasis Rev 2002; 21: 3-16.

[22] Carruba G. Estrogen and prostate cancer: an eclipsed truth in an androgen-dominated scenario. J Cell Biochem 2007; 102: 899-911.

[23] Voisey J, Morris CP. SNP technologies for drug discovery: a current review. Curr Drug Discov Technol 2008; 5: 230-5. 
[24] Chen Y, Zhu J, Lum PY, Yang X, Pinto S, MacNeil DJ, et al. Variations in DNA elucidate molecular networks that cause disease. Nature 2008; 452: 429-35.

[25] Candore G, Balistreri CR, Caruso M, Grimaldi MP, Incalcaterra E, Listì F, et al. Pharmacogenomics: a tool to prevent and cure coronary heart disease. Curr Pharm Des 2007; 13: 3726-34.

[26] Candore G, Balistreri CR, Grimaldi MP, Listì F, Vasto S, Chiappelli M, et al. Polymorphisms of pro-inflammatory genes and Alzheimer's disease risk: a pharmacogenomic approach. Mech Ageing Dev 2007; 128: 67-75.
[27] Wang RF, Miyahara Y, Wang HY. Toll-like receptors and immune regulation: implications for cancer therapy. Oncogene 2008; 27: 181-9.

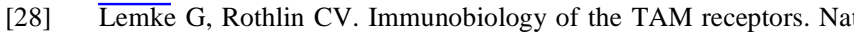
Rev Immunol 2008; 8: 327-36.

[29] Linger RM, Keating AK, Earp HS, Graham DK. TAM receptor tyrosine kinases: biologic functions, signaling, and potential therapeutic targeting in human cancer. Adv Cancer Res 2008; 100: 35-83.

[30] Perneger TV. What's wrong with Bonferroni adjustments? Br Med J 1998; 316: 1236-8. 